\title{
Por una defensa de las aguas de Wallmapu en la poesía de mujeres: Kvyeh, Figueroa y Paredes Pinda*
}

\author{
Advocacy for the waters of \\ Wallmapu in recent women's poetry: \\ Kvyeh, Figueroa and Paredes Pinda
}

María José Barros Cruz**

\begin{abstract}
RESUMEN
En el artículo se analiza - desde un enfoque próximo al ecofeminismo- un corpus de poemas de las escritoras Rayen Kvyeh, Damsi Figueroa y Adriana Paredes Pinda, en el cual se elabora un discurso a favor de la defensa de los ríos y mares de Wallmapu en el marco del Chile posdictatorial. Desde una conciencia descolonizadora alineada con la epistemología y ética mapuche, las voces poéticas visibilizan críticamente la soberanía de la muerte ejercida por el capitalismo extractivista sobre el territorio mapuche y su biodiversidad, poniendo de relieve la concepción indígena acerca del agua y replanteando políticamente los vínculos entre mujeres y naturaleza.
\end{abstract}

\begin{abstract}
We aim to analyze a corpus of poems by female writers Rayen Kvyeh, Damsi Figueroa, and Adriana Paredes Pinda. We will use an approach related to ecofeminism, wherein a discourse exists that advocates for the conservation of the rivers and seas of Wallmapu within the framework of post-dictatorial Chile. We will analyze from a decolonizing consciousness aligned with Mapuche epistemology and ethics. Poetic voices critically vi-
\end{abstract}

Palabras clave: agua, poesía, mujeres, mapuche, naturaleza.
Keywords: Water, Poetry, Women, Mapuche, Nature.

\footnotetext{
* Este artículo se enmarca en el proyecto posdoctoral Fondecyt no 3180228: "Artistas y activistas del siglo XXI: retóricas de la resistencia y genealogías descolonizadoras en Cecilia Vicuña, Ana Tijoux y Camila Huenchumil" (2018-2020), del que soy la investigadora responsable.

** Chilena. Doctora en Literatura de la Pontificia Universidad Católica de Chile. Académica de la Facultad de Artes Liberales de la Universidad Adolfo Ibáñez, Santiago, Chile.mjbarro1@uc.cl
} 
PorunadefensadelasaguasdeWallmapuenlapoesíademujeres:Kvyeh,FigueroayParedesPinda | Barros

sualize the sovereignty of death exercised by extractive capita-

lism over Mapuche territory and its biodiversity, highlighting

the indigenous conception of water and politically rethinking

the links between women and nature. 
"Un tigre he dibujado en el arroyo para que el agua libre se defienda" (90).

JAime Huenún, REDUCCIONES

\section{A modo de introducción: escuchar el canto y las voces del agua}

A mediados de los 90, Nicolasa y Berta Quintreman lideraron el movimiento de resistencia en contra de la represa Ralco, proyecto impulsado por la empresa española Endesa en los territorios pehuenche de Alto Biobío y que consideraba la construcción de seis centrales hidroeléctricas. Pese a los informes negativos acerca de las consecuencias ambientales que provocaría el megaembalse, así como los engaños y las presiones a las que fueron sometidos los miembros de las comunidades Quepuca Ralco y Ralco Lepoy para que firmaran el contrato de permutas y reasentamiento (Namuncura 171), la construcción de Ralco fue apoyada por el gobierno de Eduardo Frei e inaugurada en el 2004 bajo el mandato de Ricardo Lagos.

Luego de años de lucha y movilizaciones que reunieron a distintos actores sociales y organizaciones, las hermanas Quintreman fueron testigos de la inundación de sus tierras ancestrales y lugares sagrados, así como del desmembramiento de las comunidades indígenas afectadas por este proyecto hidroeléctrico (Bengoa 2014: 269; Benohr y Urrutia 2018). La institucionalidad política entre el pueblo mapuche y el Estado chileno se quebró y la sensación de derrota embargó a los defensores del río Biobío; sin embargo, las protestas en contra de Ralco y el ejemplo de las ñañas Quintreman marcaron un hito sin precedentes en el Chile de la posdictadura, que fortaleció al movimiento mapuche autodeterminista (Pairican 302).

He querido comenzar este artículo recordando a las líderes y activistas pehuenches, pues su lucha pone de manifiesto cómo la acción política de las mujeres del sur y su protagonismo tantas veces negado en el acontecer histórico se encuentra estrechamente vinculado con la defensa de los territorios indígenas y el autosustento para sus comunidades. Como bien señala Aimé Tapia González (2018), en las últimas décadas las mujeres indígenas se han posicionado como ac- 
tores sociales fundamentales en la lucha contra el capitalismo globalizado y la defensa de los recursos naturales, ya que son justamente ellas, los pueblos indígenas y los sectores más empobrecidos de la sociedad los principales afectados por el extractivismo. En este contexto, la académica mexicana analiza cómo las indígenas de distintos países latinoamericanos se han movilizado por la defensa de los recursos hídricos y el derecho humano al agua, concluyendo que "la crisis del agua tiene género, clase social y, muchas veces también, etnia" (241).

$\mathrm{Al}$ respecto, y en particular para el caso de Chile, basta pensar en la contaminación de los ríos provocada por la minería en el norte del país, la escasez de agua producida por la industria forestal en el sur o la contaminación de los mares ocasionada por las empresas salmoneras en Chiloé, crisis ambientales que han terminado por afectar principalmente a las comunidades indígenas, campesinas y de pescadores artesanales que dependen de manera directa del agua para su sobrevivencia. Todo lo anterior conduce a pensar que el acceso al agua, bien comunitario por excelencia (Shiva 2004), se está convirtiendo cada vez más en un privilegio o lujo de unos pocos, que beneficia especialmente a las grandes empresas dedicadas a la minería y la agricultura, así como a quienes viven en la ciudad y tienen mayores ingresos económicos. En relación con esta realidad de profunda desigualdad social, se debe considerar también que Chile y su actual modelo de gestión de aguas impuesto durante la dictadura constituye un ejemplo extremo de "neoliberalización" de los recursos hídricos a nivel mundial (Prieto 143). Como si de una mercancía o simple materia prima se tratara, los derechos de agua han sido privatizados y muchas empresas se han visto beneficiadas gracias a las escasas regulaciones en el acceso a mares y ríos.

El agua es un líquido vital en disputa y en nuestro país distintos movimientos, organizaciones sociales y comunidades han hecho suya la lucha por los recursos hídricos y un acceso democrático, sostenible e inclusivo al agua. En este contexto, escritoras y cantautoras tanto chilenas como mapuche han asumido como propia la demanda por la recuperación de las aguas, entre las que cabe mencionar a Rayen Kvyeh, Adriana Paredes Pinda, Damsi Figueroa, Roxana Miranda Rupailaf, María Teresa Panchillo, Cecilia Vicuña, María Isabel Lara Millapán, 
Maribel Mora Curriao, Daniela Catrileo, Alejandra del Río, Ana Tijoux, Daniela Millaleo y Camila Moreno, entre otras ${ }^{1}$.

Considerando la amplitud de este corpus - que he recopilado en el marco de mi investigación acerca de los cruces entre artistas mujeres y activismo-, en este artículo quisiera centrarme en una versión más acotada, que se restringe a algunos poemas de Kyveh, Figueroa y Paredes Pinda publicados entre los años 1992 y $2011^{2}$. ¿Qué tienen en común estos textos? La elaboración de un discurso a favor de la defensa de las aguas alineado con las demandas de la calle y situado geopolíticamente en Wallmapu, posicionamiento desde el cual se denuncian los daños provocados por los proyectos extractivistas emplazados en territorios indígenas. En otras palabras, se trata de producciones artísticas que ingresan abiertamente al terreno de lo político y que toman partido respecto de conflictos medioambientales concretos como la construcción de la represa Ralco o el ducto de desechos que Celulosa Arauco ha intentado instalar en las playas de Mehuín desde mediados de los 90. ¿Pero cómo es puesta en escena o textualizada esta mirada que polemiza abiertamente con la mercantilización de la naturaleza y sus aguas promovida durante el Chile posdictatorial?

A modo de hipótesis, quisiera proponer dos entradas de lectura respecto de la posición enunciativa de las voces creadas en los poemas que aquí me convocan. En primer lugar, sostengo que las hablantes articulan una retórica de la resistencia que se distancia de los discursos celebratorios de la modernidad y sus narrativas del progreso, visibilizando críticamente la lógica de la muerte ejercida sobre el territorio de Wallmapu y su biodiversidad en el marco del modelo extractivo de recursos naturales que opera actualmente en Chile. En este sentido, los trabajos de Kvyeh, Figueroa y Paredes Pinda bien podrían ser entendi-

1 Más allá de la poesía y la música, otros artistas también se han sumado a la defensa de las aguas desde otras disciplinas y soportes artísticos. Pienso en el disco Mapocho (2017) de La Chimuchina; el documental Río sagrado (2019) de Nicole Ellena y Erick Vigouroux; la instalación-performance Ko Ta Mapungey Ka (Agua también es territorio) (2020) de Sebastián Calfuqueo; las intervenciones lumínicas Ngen Ko, espíritus del agua y Ngen Kintuantü, fuerza espiritual que busca el sol (2020) del colectivo Delight Lab; y el documental video-instalación Siluetas de agua (2020) de Violeta Paus.

2 Respecto de otras artistas reunidas en este corpus mayor en torno a las aguas, específicamente Cecilia Vicuña y Ana Tijoux, sugiero ver el texto de mi autoría: "Aguas y ríos: activismo, descolonización y naturaleza en Cecilia Vicuña y Ana Tijoux". Latin American Research Review, vol. 55, no. 3, 2020, pp. 544-559. 
dos a partir del concepto de colonialidad de la naturaleza propuesto por Héctor Alimonda. Sus poemas ponen de manifiesto cómo el ciclo del agua y su entorno natural están siendo violentados con fines meramente económicos, situación que - lejos de ser reciente- da cuenta de la vigencia de una matriz colonial de poder que ha arrasado con ecosistemas enteros según las necesidades de los regímenes de acumulación capitalista (Alimonda 22) desde la conquista de América hasta nuestros días. De ahí también la posibilidad de extender la noción de necropolítica de Achille Mbembe (2001) a lo que hoy ocurre en territorios indígenas como Wallmapu, espacio subalternizado por el capitalismo global y su lógica extractiva, donde las empresas - amparadas por el Estado chileno- ejercen el "derecho de matar" (21) sobre los bosques, animales, mares, ríos y montañas. Lejos de la concepción animista de la naturaleza que predomina en las cosmovisiones ancestrales, las plantaciones forestales y las centrales hidroeléctricas han instalado una soberanía de la muerte que atenta contra las distintas formas de vida humanas y no humanas.

Por otro lado, y aquí introduzco la segunda parte de mi hipótesis, el lugar de enunciación de las voces creadas por Kvyeh, Figueroa y Paredes Pinda se encuentra enraizado en las epistemologías y éticas indígenas de Wallmapu. La defensa de los ríos y mares se realiza desde una conciencia descolonizadora alineada con la cosmovisión mapuche, en la que el agua es pensada como una entidad viva y sagrada, cuyas corrientes llenas de fuerza y energía son habitadas por animales, plantas, peces, mariscos y múltiples seres maravillosos tanto benéficos como peligrosos que conviven con los seres humanos y su entorno (Skewes y Silva 2007: 132; Skewes et al. 2012: 311 ). En los poemas seleccionados, las sujetas textuales son capaces de escuchar las voces y los cantos de los seres, espíritus y ancestros que se manifiestan en las múltiples formas del agua. Este gesto no solo problematiza el paradigma del mercado y su idea acerca del agua como una materia inerte que debe ser explotada, sino que además promueve la descolonización de nuestros sentidos, poniendo de relieve la actitud de escucha frente a los sujetos tanto humanos como no humanos ${ }^{3}$.

3 A partir de Silvia Rivera Cusicanqui y Carlos Lenkersdorf, Tapia González explica que en las epistemologías indígenas la condición de sujeto no es exclusiva de los seres humanos: "La comunicación es intersubjetiva, son sujetos no solo los seres humanos, sino 
En línea con lo anterior, y teniendo en mente el importante trabajo crítico impulsado por Mauricio Ostria desde la ecocrítica, quisiera señalar que mi aproximación a la temática de las aguas en la poesía de mujeres se relaciona más bien con el ecofeminismo, propuesta teórica y de acción que busca reformular el vínculo entre mujeres y naturaleza desde un posicionamiento verde, feminista, situado y político. Si bien al interior del ecofeminismo es posible identificar distintas corrientes, todas convergen en la siguiente premisa que dio vida a este movimiento a inicios de los 70: la existencia de una estrecha "conexión entre la explotación y degradación del mundo natural y la subordinación y opresión de las mujeres" (Mellor 13). Desde esta perspectiva que aúna feminismo y ecología, hay dos ideas que me parecen centrales para entender cómo la naturaleza y las aguas son representadas en los textos de las autoras reunidas en este artículo.

Por un lado, y siguiendo a Vandana Shiva (2001: 65-68), el patriarcado capitalista y su cientificismo reduccionista nos ha hecho creer que la naturaleza es una materia inerte que, en su condición de cuerpo "femenino", puede ser colonizada, explotada y mercantilizada, tal como ocurre hoy en día con las semillas. En contra de esta mirada predatoria, el ecofeminismo apuesta por redefinir el vínculo entre los seres humanos y su entorno natural, entendiendo que la naturaleza es, ante todo, vida. Una vida activa capaz de regenerarse por sí misma y que constituye una fuente de autosustento fundamental para las comunidades locales. Por otro lado, y como bien explica Alicia Puleo (2011), las mujeres - y en especial las mujeres pobres-son las principales afectadas por los desastres medioambientales hoy en día. Frente a esta situación, el ecofeminismo aboga por relevar el lugar de empoderamiento que las mujeres han asumido en la defensa por la naturaleza: "Las mujeres no somos solamente víctimas. También somos sujetos activos en el cuidado del medioambiental y en la construcción de una nueva cultura con respecto a la naturaleza" (Puleo 15). En este sentido, el ecofeminismo implica repensar la relación entre mujeres y naturaleza desde una dimensión activa, política y colaborativa, que visibiliza las luchas impulsadas por las líderes y los movimientos de mujeres indígenas y

también las plantas, los animales, los arroyos, las nubes y todo cuanto existe. [....] Todas y todos tienen algo que enseñar y algo que aprender de las/os otras/os. Animales, plantas, minerales, ríos, bosques también pueden ser portadores de conocimientos" (35-37). 
campesinas en distintas partes del mundo. Con esto no quiero decir que las poetas aquí estudiadas sean ecofeministas ni algo parecido, sino que el ecofeminismo funciona como un prisma o lente de lectura que, en parte, me ha sido útil para abordar los cruces entre naturaleza, literatura y género.

En este contexto, me parece importante mencionar también que algunas escritoras reunidas en el corpus mencionado más arriba se caracterizan por operar, al mismo tiempo, como activistas. Tal es el caso de Kvyeh y Paredes Pinda, poetas mapuche que entran y salen de sus respectivos territorios de creación para dialogar estrechamente con las demandas de los movimientos sociales y comunidades indígenas en la lucha por sus territorios, asumiendo una posición fronteriza entre la esfera artística y las voces de la calle. Su compromiso con las reivindicaciones políticas e identitarias del Wallmapu se hace visible no solo en sus producciones literarias, sino también en sus gestos de cooperación y participación en instancias de carácter público como marchas, cartas abiertas, encuentros académicos y festivales poéticos, donde vuelven explícito su apoyo a las distintas causas que hoy movilizan al pueblo mapuche y otros sectores sociales. En este sentido, resulta iluminador prestar atención al trabajo de Fernanda Moraga (2010), crítica que se ha dedicado a sistematizar y estudiar la poesía mapuche de mujeres, quien sostiene que la emergencia de este grupo de autoras se produce a inicios de los 90 en estrecho vínculo con el protagonismo político que las mujeres indígenas adquieren en la última década del siglo XX (221).

En consecuencia, podemos señalar que estamos frente a producciones literarias que elaboran una retórica de la resistencia que vuelve porosos los límites entre el arte y lo político, el artista y la comunidad, el arte y la vida, instalando una posición crítica y disidente frente a las nuevas colonizaciones de la biodiversidad propiciadas por el capitalismo transnacional. En este sentido, las voces de las poetas reunidas en este trabajo hacen eco de las movilizaciones tanto locales como globales a favor del agua, recurso de la naturaleza concebido por estos colectivos como un bien comunitario que debe ser cuidado y respetado en beneficio de todos. Escuchemos, entonces, el canto y las voces del agua que estas artistas han sabido vehiculizar a través de sus poemas e intervenciones públicas. 


\section{Poesía por las aguas libres de Wallmapu}

El hecho de que todas las poetas que aquí nos convocan - Kvyeh, Figueroa y Paredes Pinda- escriban textos en torno al Biobío no es casual. Ello se relaciona, en primer lugar, con las represas que desde la década de los 90 se comenzaron a construir sobre las aguas del río ${ }^{4}$, pero también con el significado histórico y cultural que el Biobío posee para el pueblo mapuche. Durante casi 300 años, este río fue la frontera histórica entre españoles y mapuche, siendo oficializada como tal por la Corona Española en el Parlamento de Quilín celebrado en 1641. De esta manera, se reconocía la existencia de un territorio mapuche independiente de la Capitanía General de Chile, estatuto que se mantuvo una vez lograda la independencia hasta la ocupación de la Araucanía (1861-1883), cuando el Estado chileno decidió invadir y colonizar el territorio mapuche situado al sur del Biobío (Chihuailaf 1999: 71; Bengoa 2000: 262).

Ahora bien, junto con este significado histórico vinculado con la autonomía territorial y política del pueblo mapuche, el río Biobío posee también una trascendencia cultural y social. Como bien explican Jens Benohr y Paulo Urrutia, según las creencias mapuche existe un gran río terrenal, el Biobío, en cuyos brazos y riberas se fueron asentando numerosas familias y linajes. Su equivalente espiritual es el gran río del cielo, el Wenuleufü (Vía Láctea), donde habitan los primeros antepasados que poblaron la tierra. Este relato, sostienen Benohr y Urrutia, "pone de manifiesto el rol articulador del río Biobío para la sociedad mapuche" (s/p). Considerando lo anterior, no resulta difícil comprender la gran resistencia que desencadenó la construcción de un megaembalse como Ralco y la consecuente emergencia de producciones literarias, cinematográficas, musicales y visuales en defensa del

4 A propósito de las tres las represas construidas en el Biobío, Jens Benohr y Paulo Urrutia señalan: "En los años 60 Endesa —entonces empresa pública-, determinó que podían construirse allí seis centrales. El bosquejo estaba hecho, pero comenzó a ejecutarse en los 90, con la compañía ya privatizada. Así, en estas tres últimas décadas, el río Biobío ha pasado de ser una de las cuencas más grandes de Chile, a ser la cuenca de sacrificio más grande del país, debido a la construcción de tres megaembalses: Pangue, Ralco y la recientemente inaugurada central Angostura, inundando enormes superficies de bosque nativo y cementerios sagrados para el pueblo pehuenche" (s/p). 
rí $^{5}$, cuyas primeras representaciones en la poesía chilena podemos rastrear en el Poema de Chile (1967) de Gabriela Mistral ${ }^{6}$.

Respecto de la poesía de Rayen Kvyeh - poeta y dramaturga, prisionera política durante la dictadura, fundadora de la editorial y revista Ñuke Mapu y organizadora desde el 2012 del Festival de Poesía de Wallmapu (Sánchez, "Los esbirros..." 24) - quisiera centrarme en dos poemas que tematizan la defensa de las aguas desde la siguiente premisa: lo que hoy se vive en Wallmapu es una nueva "pacificación" por parte de las grandes empresas del capitalismo extractivista y el Estado chileno. De ahí el título de su última publicación, Pazcificación del Wallmapu (2017), libro testimonial y de denuncia en el que se relatan los procesos judiciales enfrentados por los presos políticos mapuche durante la década del 2000 y a quienes la poeta se refiere como "los defensores de la tierra" (10). Los textos a los que haré referencia son "Fiu Fiu (Biobío)" y “La obscuridad del agua", ambos publicados en su poemario Luna de cenizas del año 1992.

En “Fiu Fiu (Biobío)", la voz polemiza abiertamente con las represas que a inicios de los 90 se proyectaba construir sobre las aguas del río Biobío, siendo importante señalar que en 1992 la central hidroeléctrica Pangue ya se encontraba autorizada, pese a la desaprobación de las comunidades indígenas y movimientos ciudadanos: "Corren los ríos como sangre por la tierra/ llevando los sueños de mis abuelos/ alimento de nuestra liberación./ Por eso Biobío/ te encarcelan en represas" (24). Asumiendo una enunciación colectiva, las represas son caracterizadas como una amenaza frente al deseo de libertad del pueblo mapuche, inculcado por los ancestros y transmitido por las corrientes torrentosas del "FUXALEUFU" (24), nombre antiguo que significa "gran río", dicho visualmente en el uso de mayúsculas. Al igual que una cárcel, estos embalses obstruyen e inmovilizan el fluir libre del río, lo que se condice con el paradigma de mercado y su idea del agua como un

$5 \quad$ Más allá de lo estrictamente literario, incluyo en este corpus de artistas movilizados por Ralco los documentales Punalka, el Alto Bío Bío (1995) de Jeannette Paillán y Ralco (2000) y El velo de Berta (2004) de Esteban Larraín; la serie de pinturas Toda la magia del sur (2012) de Papas Fritas, en donde se incluye un homenaje a la ñaña Nicolasa Quintremán; y el disco El Biobío sigue cantando (1996), que reúne canciones inéditas de Joe Vasconcellos, Illapu, La Pozze Latina, Fulano y Congreso, entre otros músicos.

6 Me refiero a los poemas "Ya se ve ya, el Bío-Bío" y "Bío-Bío". 
cuerpo inerte que puede ser aprisionado para su explotación ${ }^{7}$. De ahí también el poema "Hombre moderno", en el que se retrata con ironía la codicia del dueño de una central hidroeléctrica quien, desde su "lujosa mansión", decreta el aprisionamiento de las aguas: "Sus proyectos de vida/ traducidos en dinero/ esperan la orden de ejecución:/ ¡Prisión de las aguas/ en modernas represas!” (51). Por cierto, este imaginario colonizador en torno a las aguas se distancia de la idea del río como un torrente-sangre vital, fecundo y lleno energía que corre por el cuerpo viviente de la Madre Tierra.

Considerando lo anterior, me parece importante detenerse también en el título del poema, pues en este se rescata el origen onomatopéyico del nombre del río asociado con el canto del pájaro fiu fiu (Zeyla Mora 52). Mediante este gesto, Kvyeh pone de relieve no solo los saberes ancestrales y lingüísticos vinculados con este importante caudal de Wallmapu, sino también la idea de una naturaleza sonora, profundamente viva y en la que todos los seres - aguas, aves y humanos- están comunicados entre sí. Desde esta perspectiva, si hay algo que caracteriza la representación del Biobío en este texto poético es su fuerza movilizadora y conexión con otros elementos de la naturaleza como las araucarias o la nieve, pero también la idea de que sus aguas son testigos de la historia y transmisoras de las voces y cantos de los ancestros: "Hombres extranjeros/ no ven el palpitar de nuestra historia/ en tus aguas./ Quieren detener tu canto/ y acallar nuestras voces ancestrales" (51). Las aguas, en este sentido, son portadoras de una memoria colectiva y viva para el pueblo mapuche, que los winka - siempre nombrados en su condición de "hombres", por tanto, como agentes del patriarcado- son incapaces de ver, escuchar y valorar.

Por otro lado, en el poema “Obscuridad del agua”, Kvyeh denuncia la sequía y el aislamiento sufrido por las comunidades mapuche de la

$7 \quad$ La imagen de la represa como una cárcel elaborada por Kvyeh me recuerda a otra artista-activista defensora de las aguas, Carolina Caycedo, y su proyecto Represa-represión (2013) motivado por la construcción de la central hidroeléctrica El Quimbo en el río Magdalena. Desde la homologación etimológica propuesta en el título, en este trabajo se establece una analogía entre la construcción de represas - grandes estructuras de ingeniería que reprimen las aguas- y la represión de los movimientos sociales y comunidades que, situados en contextos específicos, se oponen al capitalismo transnacional que promueve este tipo de proyectos extractivistas.

8 Este poema forma parte de la sección "Mentiras modernas" escrita en el 2000 e incluida en la versión del 2011 del libro Luna de cenizas. 
comuna de Lumaco a causa de la industria forestal, recurriendo para ello a los recuerdos y la voz testimonial del lonko Ricardo Cayupán, con quien la poeta se entrevistó a inicios de los $90^{9}$. Por medio de un contrapunto entre pasado y presente, se va relatando en el texto cómo las pocas tierras con que se quedaron los mapuche luego de la ocupación de la Araucanía a fines del siglo XIX transitaron desde la abundancia de agua hacia el estado actual de sequía. Desde esta perspectiva, el lonko rememora el tiempo de las reducciones vivido por sus abuelos, cuando el agua aún brotaba con abundancia y nutría con su fuerza las plantaciones de trigo, la chacra familiar y los animales: "El lonko Kayu$\mathrm{pan} / \mathrm{se}$ remonta en sus recuerdos./ Mis abuelos tomaron las semillas,/ en la poquita tierra que nos dejaron/ sembraron trigo./ Había agua en abundancia./ El Koilako corría ondisonante/ y sus voces llenaban de vida este valle.// El sagrado poder del agua/ estaba sobre nuestra mapu ñuke" (36).

Pero la abundancia de agua, alimentos y animales se convierte en pobreza, enfermedad y sequía cuando los "winka" se apropian ilegítimamente del territorio para plantar pinos: "El lonko Kayupan continúa/ anudando la historia./ Desde que llegaron los winka,/ que no son los dueños de la tierra,/ acorralaron la comunidad mapuche,/ con plantaciones de pino./ [...] El pino produce enfermedades./ [...] El sagrado poder del agua/ se ha refugiado, enfermo,/ muy abajo en el vientre de nuestra madre tierra" (37-38). En la actualidad, las plantaciones de pinos y eucaliptus situadas en localidades como Lumaco no solo han propiciado el aislamiento e incomunicación de las comunidades mapuche, sino que además han ocasionado una grave crisis hídrica que se traduce en la escasez y contaminación de las aguas ${ }^{10}$. En el poe-

9 En el texto "Todo termina, pero la tierra nunca termina, siempre se queda" de Kvyeh, publicado en la revista Ñuke Mapu en 1990, la escritora relata la historia de Lumaco y reproduce parte de la conversión sostenida con el lonko Ricardo Cayupan. Algunas partes de este testimonio fueron incorporadas posteriormente en el poema "Obscuridad del agua". Un antecedente importante que no se incluye en el poema es la narración acerca de la toma del fundo Santa Clara ocurrida el 10 de octubre de 1989 por parte de las comunidades mapuche de Lumaco en el marco del proceso de recuperación de tierras y que fue duramente reprimida por la policía.

10 Siguiendo a Pairican, durante los años 90 "Uno de los mayores problemas de aquella comuna [Lumaco] era la sequedad de las napas subterráneas causada por la acción forestal. Esto conllevaba la escasez de agua tanto para la subsistencia como para la agricultura. La fumigación de las forestales se tradujo en el envenenamiento de los pastos y cultivos. Las mismas plantaciones y los caminos que se construyeron para trasladar los 
ma, lo anterior se observa en el testimonio del lonko y su visión acerca de los monocultivos como la causa de un desequilibrio del entorno natural que produce enfermedad, es decir, un daño en el cuerpo de la tierra y en quienes dependen de ella para subsistir. De ahí la representación del agua como un espíritu debilitado y "enfermo", mensaje de la naturaleza y llamado de alerta que Kvyeh busca transmitir desde su escritura poética.

A propósito de Damsi Figueroa - poeta nacida en Talcahuano, pero vinculada con la producción literaria de Concepción (Gallardo, "Visión del..." 2005: 95-96) y con la generación de los 90 bautizada como "los náufragos" (Bello 1998) - me centraré en los poemas "Mehuín 2006" y “Quepuka Ralco 1996", ambos publicados en la antología Lof Sitiado de Jaime Huenún. Si bien Figueroa no forma parte de la escena literaria mapuche, ella es una escritora que desde temprano entabló contacto con la cultura mapuche y su amor por la tierra. En la entrevista publicada en Valija Cultural, la poeta cuenta que durante su niñez "vivía en un territorio mapuche casi sin saberlo" (s/p), pero que al tomar consciencia de esta situación comenzó a interesarse en la lengua y cultura de sus "vecinos", llegando incluso a "trabajar en varios proyectos comunitarios y educativos en Alto Biobío, Licanray, Coñaripe, Tirúa y Traiguén" (s/p). Esta cercanía con el pueblo mapuche y su "cultura del agua" ${ }^{11}$ se observa en los poemas que aquí analizaremos.

En "Mehuín 2006", Figueroa hace una referencia explícita en el título del poema al poblado costero del sur del país ubicado en la Región de los Ríos, que desde 1996 vive bajo la amenaza de la construcción de un ducto para evacuar al mar los desechos de Celulosa Arauco. Como bien explica Héctor Nahuelpan (2016), desde entonces los pescadores artesanales, las comunidades mapuche-lafkenche y

pinos y eucaliptus de la Celulosa Arauco, significó, para los mapuche, quedar cercados por estas miles de plantaciones de veinte metros de altura, impidiendo el acceso a los caminos para llevar a pastorear sus animales" (95).

11 En su texto Las guerras del agua, Shiva explica que la crisis del agua que el mundo vive actualmente se debe a un choque entre dos "culturas del agua", es decir, "formas distintas de entender y sentir el agua" (9). Por un lado, desde el paradigma ecológico, el agua es concebida como un "don gratuito" otorgado por la naturaleza y como un bien comunal (53); por el contrario, desde el paradigma del mercado, se considera que "el agua es una mercancía, y su propiedad y comercio un derecho fundamental de las empresas" (10). 
otros actores sociales de esta localidad se han movilizado para hacer frente a este proyecto que constituye una amenaza directa a su principal fuente de sustento: el mar. A partir del despliegue de distintas estrategias de resistencia, especialmente el control territorial, los defensores del mar han impedido la construcción del ducto en Mehuín, convirtiéndose en "un referente de organización y movilización que, desde abajo y articulando una diversidad de actores, buscaba contener las transformaciones que proyectos de inversión pública y privada producían en territorios locales durante el contexto democrático posdictatorial" (Nahuelpan 102). Desde esta perspectiva, leo la fecha indicada en el título del texto como un homenaje a los pescadores que en el año 2006 "lograron expulsar tanto a las embarcaciones de la Armada como a las de la empresa que pretendían realizar estudios de batimetría" (101). La mención a Mehuín, entonces, constituye un gesto de reivindicación de las luchas locales, colectivas y territoriales por la defensa del $\operatorname{mar}^{12}$.

Después del título, el poema se configura como una suerte de elegía en que la voz se lamenta por la muerte de los ríos, mares, lagos, bosques y pueblos ocasionada por empresas que, desde una lógica extractivista y con el apoyo del Estado chileno, ejercen sobre las vidas humanas y no humanas su soberanía de la muerte: "Cada día en Chile muere un río./ (Cada día Chile mata un río).// Cada día un bosque muere/ y en su tumba es suplantado/ por un ejército de eucaliptus y pinos.// Ay de mi país sin agua, río Cruces, Laja, Itata, Mataquito, Biobío.// Cada día en Chile muere un lago,/ envenenado por la peste/ de los peces asesinados, medicados..." (76). Como se puede advertir, el Chile de la posdictadura es representado como un país que, sumido en su credo neoliberal, ha privilegiado el éxito económico por sobre el resguardo de su biodiversidad, cometiendo un acto homicida en contra de la naturaleza. De ahí la rectificación al primer verso del poema realizado en el paréntesis que le sigue, donde

12 La poeta Cecilia Vicuña también ha asumido un discurso de defensa del mar en sus producciones audiovisuales recientes. Pienso, por ejemplo, en La muerte del mar (2010), video que pone en escena las consecuencias de la pesca de arrastre en la costa del litoral central y la lucha de los pescadores artesanales, cuya genealogía Vicuña reconstruye a partir de los changos y en diálogo con el baile de los chinos. A su vez, este video es un homenaje a Mistral y su poema "Muerte del mar" publicado en Lagar (1954). 
la hablante sitúa a Chile como el sujeto de un asesinato: la muerte de un río. En pocas palabras, estamos hablando de un país que está convirtiendo su riqueza territorial en zonas de sacrificio ambiental, es decir, en ciudades y poblados habitados especialmente por sectores sociales precarizados que son condenados a sufrir la devastación y contaminación de su entorno. Tal es el caso del río Cruces en Valdivia mencionado en el poema, donde Celulosa Arauco depositó sus desechos en 2004 provocando un desastre ecológico que le costó la vida a cientos de cisnes de cuello negro y más de dos mil peces, poniendo en riesgo además la salud de las personas del sector (León s/p).

En coherencia con esta mirada crítica respecto del accionar de las empresas, en el texto poético “Quepuka Ralco 1999” Figueroa construye la voz de un testigo, quien relata cómo fue vivida la construcción de la represa Ralco por parte de las comunidades pehuenche afectadas por este proyecto extractivista. Como si se tratara de una crónica, la hablante recurre con insistencia al tiempo verbal presente y a un imaginario bélico para decirnos que Ralco constituye para los mapuche una nueva colonización de sus tierras por parte de los españoles, quienes ahora regresan como los dueños de Endesa, responsables de la construcción de la central hidroeléctrica:

Vienen las huestes españolas a estrangular la garganta del Fiw fiw./ Traen dinamita, quieren socavar la selva, el pellejo todo/ roer la faz de la montaña./ Cascos blancos. Marchan sólidas las filas de ingenieros./ Ya vienen los colosos y son mil los yanaconas alistados./ Ya se acercan los camiones,/ suben cables, suben muerte en su invencible maquinaria. (77)

Lo que el fragmento citado deja entrever es que tras la construcción de Ralco subyace una lógica propia de la guerra (palabras como "huestes", "marchan", "alistados" e "invencibles maquinarias" dan cuenta de ello) y que la violencia ejercida en Alto Biobío responde a un proceder colonial y patriarcal. En otras palabras, estamos en presencia de hombres-soldados que, confiados en sus saberes ingenieriles y nuevas tecnologías, se sienten con la potestad de conquistar, explotar y destruir tierras ajenas, arrasando a su paso con el bosque nativo y sus árboles "milenarios": "Palmo a palmo se sucede la batalla. Polvo, estruendo./ Caen peumos, lleuques, pehuenes milenarios” (77). 
Frente a la soberbia y violencia de los nuevos invasores, la respuesta pacífica de las comunidades mapuche será ilustrada en la figura de Berta Quintremán, líder de la resistencia contra Ralco, quien - acompañada de "su ejército de árboles y pájaros" (77) — recurre a la práctica espiritual del conjuro para defender su territorio: "A un costado del camino, a un costado de la herida/ Berta Quiltremán/ dice al viento sus conjuros.// (Esa fue nuestra estrategia/ Erguirnos desnudos bajo la lluvia./ Esa/ Fue)" (77). De acuerdo con lo señalado por la voz, los habitantes de Alto Biobío depositaron su confianza en el poder de la palabra subversiva, mágica y dicha entre dientes; en la fuerza de las mujeres que se opusieron al reasentamiento de las comunidades; en la lluvia, el viento, los pájaros y los árboles como aliados de los defensores de la tierra. Todo lo anterior no hace más que poner en evidencia el choque entre dos maneras antagónicas de pensar y relacionarse con la naturaleza, representadas, por un lado, en los agentes de la represa y, por otro, en las comunidades indígenas de Alto Biobío.

Por otra parte, con Adriana Paredes Pinda, poeta y machi de la comunidad de Kallfullanka, resulta importante reparar en su condición de "mapuche champurria" (Paredes, "La pluma del picaflor" 175) desde la cual concibe su propia biografía y proyecto escritural. Consciente del ultraje lingüístico sufrido por el pueblo mapuche, en el texto "De por qué escribo... Mollfvñ pu nvtram" - arte poética con que introduce su libro $\ddot{U} i$ (2005) - reflexiona acerca de la doble filiación que marca su poesía, tensionada entre la escritura y el canto, el español y el mapudungun, el mundo huinca y el mundo mapuche, así como las contradicciones que emergen desde quien se sabe habitando una zona fronteriza, mestizada y siempre en conflicto: "escribo porque tal vez es cierto que tengo dos corazones [...]. Escribo porque seguro no puedo cantar; si cantara solo tendría un piuke [...] no logro zafarme del hechizo de esta escritura huinca porque me arranca y me arranca el aliento..." (7). Considerando el lugar de enunciación "impuro" que caracteriza la obra poética de Paredes Pinda, quisiera analizar a continuación algunos fragmentos de $\ddot{U} i$, específicamente, la tercera y última sección titulada "Biobío" — que reúne 32 poemas numerados- y el texto final "Gen ko / La palabra del dueño del agua". En esta última parte, la poeta nos sitúa "en el centro del conflicto histórico que separa 
al pueblo mapuche del Estado chileno" (García, "El proceso de..." 63), asumiendo un discurso de resistencia y lucha en contra de la central hidroeléctrica Ralco, permeado por su experiencia de machi y vínculo personal con el Biobío ${ }^{13}$.

Para entender cómo Paredes Pinda elabora su defensa de las aguas y del río Biobío en su segundo poemario, quisiera remitir a la iluminadora lectura de Mónica Munizaga (2011) referida a la identidad de machi asumida por la voz poética: "la sujeto lírica es análoga a la machi, por lo tanto, la voz de la enunciación está en conexión con lo sagrado por medio del estado de éxtasis chamánico, siendo la escritura el trance y, a la vez, el canal por el cual transmite los mensajes recibidos" (11). La hablante se convierte en intermediaria entre su comunidad y las voces de los ancestros y espíritus de la naturaleza que hablan a través de ella, cumpliendo con el rol que las machi de su familia le han concedido y enseñado (22). En este contexto, ella sostiene una especial conexión con los espíritus y seres que habitan el agua - conversa con las vertientes, escucha el llanto de las shumpall, sueña con Punalka-y se comunica con los antiguos guerreros como Kvlapag y Juan Ignacio Maripe, que la acompañan en su lucha por la defensa del río. De ahí el carácter polifónico y dialógico de su discurso, en el que se cruzan e imbrican múltiples voces ajenas, relatos orales, conversaciones y enseñanzas de las ñañas del Alto Biobío como Nicolasa Quintreman y Panchita Curriao o de sus antepasadas machi como Filipa, pero también los cantos, resuellos y voces que emanan de las corrientes, animales y plantas del lugar.

De acuerdo con la experiencia de machi vivenciada por la voz poética, en los textos de esta tercera sección abundan las descripciones de sueños y visiones que contienen mensajes, presagios y advertencias para la comunidad. En el primer poema, por ejemplo, el canto deviene

13 En "La pluma del Picaflor del agua", texto de carácter testimonial y biográfico, Paredes Pinda explica que su vida está atravesada por dos ríos: el Rahue, el río de su infancia, y el Biobío (176). Las anécdotas contadas a propósito de su devenir machi dejan entrever que este último río tiene un significado especial para ella, ya que fue durante la construcción de Ralco y en Alto Biobío donde se encontró con su espíritu de machi: "Fueron años muy movidos, porque el tema de Ralco en esos años generó un movimiento tremendo; de hecho, la primera vez que yo entré en trance fue en Ralco, en el marco de la construcción de la represa. Allí donde yo entré en trance ahora está todo inundado: Ralco Lepoy, se llevaron a los pewenche usurpados, a El Barco, a morir de nieve, hambre y pena" (186). 
en una visión apocalíptica de la construcción de la central hidroeléctrica dicha en la presencia de la muerte: "Entonces ardiendo/ dentro de mí/ la vi: era la muerte que venía" (43). Los fundos de reasentamiento como El Barco ${ }^{14}$, lejos de las falsas promesas de Endesa, son representados como los espacios de precarización, pobreza y sequía que realmente eran: "Los hombres ya/ desposados/ por el hambre/ Endesa y El Barco/ prometedores/ arrecifes de la sed" (44). Mientras tanto, el Biobío y las shumpall del río Pilmaiquén lamentan el ultraje y el olvido de sus aguas: "El Biobío/ muerde/ también/ su cándida amalgama de peñasco delirio y abandono/ ah, Biobío/ resuella el mundo a tu azul crin/ Pilmaiquén/ se escuchan tus shumpall/ llorar..." (50). Todo en el discurso de la hablante indica que la represa constituye una grave alteración no solo del entorno natural del Biobío, sino también del orden social y cultural de las comunidades pehuenche asentadas en su ribera.

Pese a lo anterior, en los 32 poemas dedicados al Biobío y el poema "Gen ko / La palabra del dueño del agua" la voz poética articula un discurso de resistencia centrado en la fuerza de lo colectivo y el poder de las aguas. Frente a la violencia de la represa, la hablante hace un llamado a la comunidad para congregarse en la montaña y realizar juntos una rogativa por la liberación del río: "subiremos /llafllaf juntos todos /[...] subiremos /Biobío /pies /danzantes /subiremos /cántaros, troko metawe rali /subiremos /y /Endesa /veremos /C /A /E /R" (45). La lucha contra Endesa debe emerger desde lo colectivo y la revitalización de las prácticas rituales donde los seres humanos bailan, cantan y hacen ofrendas para pedir por el restablecimiento del orden cósmico. "Cuando hacemos rogativa - dice el Genpin- /entonces sí florece el espíritu del Biobío" (92), nos recuerda la voz. Pero esta acción debe ir acompañada por las fuerzas espirituales que nacen desde la misma naturaleza y los seres que habitan en ella. Lejos de todo derrotismo, la

14 La precariedad a la que se verían expuestas las familias reasentadas en el fundo El Barco fue advertida por la Corporación Nacional de Desarrollo Indígena, Conadi en 1998, tal como consigna Namuncura en su libro: "en el caso de aquellas solicitudes cuyas familias deberán ser trasladadas al Fundo El Barco, los informes de Conadi indican que los niveles de sustentabilidad en dicho fundo son muy precarios y de alto riesgo para la estadía y cotidianeidad de las familias. El Barco está a poco más de 900 metros sobre el nivel del mar. Tratándose de cordillera, nieva intensamente la mayor parte del año, afectándose con ello la capacidad de cultivo y de forraje para los animales" (25). 
hablante asume la función de comunicar y persuadir a su comunidad acerca de la persistencia del poder y la fuerza del agua. "Gen ko mvley" (53) es el mensaje repetido en distintas oportunidades por la aprendiz de machi. En este contexto, la sujeto textual será la encargada de anunciar el regreso de Punalka ${ }^{15}$, el espíritu del Biobío, quien "partió/ a buscar/ fuerza al mar, dicen" (66) y que como un niño vuelve "a/ morder/ la luna/ con sus dientes de leche" (68), imagen nutricia que anuncia la recomposición del vínculo filial y la vida.

Llegamos así al poema final de $\ddot{U} i$-el único escrito en mapudungun y español- donde la voz viaja en sueños por el río Mapocho, Biobío, Cautín y Rahue y se comunica con Gen ko, el espíritu del agua: "Grandes ríos hay en mi territorio. /Algunos son madres y padres los otros. /Ellos dos conversan a lo antiguo. /El dueño del agua nos habla mientras todo se azula alrededor" (91). En coherencia con las creencias indígenas en torno al carácter divino y animado de las distintas manifestaciones terrestres (Reyes 104), los ríos asumen condiciones humanas y son ellos mismos quienes cuentan a la hablante que "La fuerza del agua ha regresado" (91) para hacer frente a la degradación ambiental producida por las invasiones huinca y sus falsas ideas de progreso. Cito a modo de ejemplo lo que la machi relata acerca de su encuentro con el río Rahue: "El dueño del agua vive en el Rahue. /Pero hoy está sucio el río /por la contaminación huinca /una industria Frigorífico arroja en el Rahue /sus desperdicios. Sin embargo, /florece el toro y la shumpall" (95).

En este y otros fragmentos del texto, el retorno del agua y su newen es metaforizado por medio de imágenes relativas a una naturaleza capaz de engendrar vida (se repiten los verbos brotar y florecer), animales vigorosos como el toro y el caballo, y la visión de seres mitológicos como las shumpall, Punalka o Mankian. "Así es abuelo, escucho tu palabra, tu palabra piñón pewenche" (93), le dice la voz a su querido Biobío, demostrando que ya ha digerido el alimento sagrado contenido en las voces y cantos de los ríos ancestrales. Investida de estos nuevos saberes, el discurso de resistencia articulado a lo largo

15 Para profundizar en el relato sobre Punalka sugiero ver el documental homónimo de Jeannette Paillán, en el que se reproducen textos de Leonel Lienlaf que hablan sobre el espíritu del Biobío y lo que sus abuelos le contaron al respecto. 
del poemario adquirirá hacia al final un tono profético y esperanzador dicho en la metáfora de la luz y desde el cual se anuncia el levantamiento de las aguas y sus guerreros: "Subirá la raíz del agua con todos sus konas /se irá la sombra huinca que la ensucia. /Las flores alumbran como relámpagos el agua" (96). El poemario, entonces, concluye con la convicción de que "El dueño del agua vive en nuestro corazón mapuche" (96).

\section{Para concluir: la naturaleza es poderosa, el agua es vida}

Durante el estallido social que se inició en Chile el 18 de octubre de 2019, una de las demandas que el movimiento ciudadano visibilizó en el espacio público fue la defensa de las aguas. "Devuelvan el agua", "Aguas libres" o "Liberen el agua" son algunos de los escritos que se podían leer por aquellos días en los muros y calles de Santiago. Esta demanda que hoy se ha instalado con fuerza en la sociedad chilena y que ha adquirido cada vez más relevancia en el marco del proceso constituyente, ya estaba siendo escrita por poetas chilenas y mapuche desde los inicios de los 90, llegando a constituirse en una temática crucial de múltiples producciones literarias - pero también de otras artes- recientes. Lo anterior, por cierto, no compete solo a Chile, sino también a otros países y territorios en donde la demanda por la conservación de los ríos y mares y el derecho humano al agua se hace escuchar en las calles y creaciones de distintos artistas. Pienso en el trabajo impulsado por la artista visual Carolina Caycedo en el río Magdalena o en películas como Río Verde: el tiempo de los yakunuras de los hermanos Álvaro y Diego Sarmiento y El abrazo de la serpiente de Ciro Guerra, estas dos últimas situadas en la selva del Amazonas, entre otros ejemplos. De ahí la proyección de abrir este estudio acerca de las representaciones del agua en la poesía de mujeres chilena y mapuche a un enfoque transdisciplinar que incluya un corpus más amplio de producciones latinoamericanas.

Como hemos podido ver en las páginas anteriores, Kvyeh, Figueroa y Paredes Pinda son escritoras que, desde distintas retóricas y textualidades, convergen en la elaboración de un discurso en defensa de los ríos y mares de Wallmapu en el marco del Chile posdictatorial. Lejos de concebir los recursos hídricos como una mercancía, las voces creadas 
por estas poetas nos recuerdan que el agua es una entidad viva, poderosa, llena de fuerza y libre, en cuyas corrientes es posible escuchar las voces de los ancestros, los espíritus de la naturaleza y otros seres vinculados con el cuidado de las aguas. En este sentido, sus proyectos escriturales no solo promueven la descolonización de nuestros saberes y sentidos respecto de la naturaleza, sino también una mirada crítica en torno a la globalización neoliberal y su afán por privatizar un bien comunitario y vital como lo es el agua. Frente al derroche y la escasez hídrica provocada por las empresas forestales, centrales hidroeléctricas y mineras, sus obras poéticas apuestan por una cultura ecológica del agua de raíz indígena. Algunas lo realizan desde una escritura más próxima a lo testimonial (Kvyeh), otras desde una textualidad champurria (Paredes Pinda) o bien desde la apropiación de géneros como la elegía y la crónica (Figueroa).

En coherencia con todo lo anterior, propuse al inicio de este trabajo que las hablantes de Kvyeh, Figueroa y Paredes Pinda asumían una posición enunciativa que, por un lado, se caracteriza por articular una retórica de la resistencia en contra de la lógica necropolítica ejercida en territorios indígenas y, por otro, que su defensa de las aguas emerge desde una conciencia descolonizadora enraizada en las epistemologías y éticas mapuche. En este sentido, parece importante recalcar que la respuesta de estas poetas frente a la destrucción y muerte de la naturaleza propiciada por el capitalismo extractivista se condensa en una estrategia que es discursiva y epistemológica a la vez: hacer hablar al agua y permitir que nosotros, en cuanto lectores, podamos escuchar sus mensajes. Más allá de toda estrategia retórica próxima a la personificación, lo que estas y otras poetas hacen en sus textos es crearle una voz a los ríos y los mares, o bien, poner en escena a mujeres que han sido capaces de escuchar sus cantos y voces. El agua, entonces, es representada como un ser animado y vital que pide ser oído y que las poetas han hecho fluir en su escritura. Después de leer estos poemas la forma de vivir, escuchar y pensar las aguas — ríos, mares, lagos, menoko, esteros- es y será otra.

Por otro lado, las poetas aquí estudiadas dan cuenta en sus textos del compromiso personal que han asumido con el territorio Wallmapu y su biodiversidad, reivindicando al mismo tiempo la lucha de líderes indígenas como Berta y Nicolasa Quintreman y Panchita Curriao, entre 
otras. En línea con el ecofeminismo, leo sus escrituras como un acto de visibilización del accionar político de las mujeres en defensa por sus territorios, lo que a su vez implica un cuestionamiento a los binarismos patriarcales masculino/femenino-cultura/naturaleza-actividad/ pasividad que neutralizan y borronean el agenciamiento femenino. Sus textos, entonces, constituyen un ejercicio de contramemoria femenino, en el que se van tejiendo múltiples voces, recuerdos e historias de comunidades que han resistido a la depredación de la naturaleza y la violencia colonial que todavía se ejerce en Wallmapu.

En este contexto de antiguas y nuevas violencias coloniales-patriarcales, muchas mujeres siguen poniendo el cuerpo y la voz. Pienso en casos más recientes como el de las activistas indígenas Macarena Valdés en Chile o Berta Cáceres en Honduras, mujeres asesinadas por luchar contra la construcción de centrales hidroeléctricas en los ríos Tranguil y Gualcarque, respectivamente, y que no pueden seguir ocurriendo ni quedando impunes.

La naturaleza es poderosa. El agua es vida. Vayan estas palabras en homenaje a las mujeres que han semillado el amor por la Ñuke Mapu y las aguas libres.

\section{Referencias bibliográficas}

Alimonda, Héctor. "La colonialidad de la naturaleza. Una aproximación a la ecología política latinoamericana". La naturaleza colonizada. Ecología política y minería en América Latina. Coord. Héctor Alimonda. Buenos Aires, Clacso, 2011, pp. 2158.

Bello, Javier. "III. Las agrupaciones: entre la afirmación y la negación". Los náufragos. 1998. Recuperado de: http://www.uchile.cl/ cultura/poetasjovenes/naufragos3.htm

Bengoa, José. Historia del pueblo mapuche. Santiago de Chile, LOM ediciones, 2000.

Mapuche, colonos y Estado nacional. Santiago de Chile, Catalonia, 2014.

Benohr, Jens y Pablo Urrutia. "Río Biobío: una historia de degradación y sacrificio". Ladera Sur. 2018. Recuperado de: https://laderasur.com/articulo/rio-biobio-una-historia-de-degradacion-y-sacrificio/ 
Chihuailaf, Elicura. Recado confidencial a los chilenos. Santiago de Chile, LOM ediciones, 1999.

Figueroa, Damsi. “Mehuín 2006", “Quepuka Ralko 1999”. Lof Sitiado. Homenaje poético al pueblo mapuche de Chile. Comp./ed. Jaime Huenún. Santiago de Chile, LOM ediciones, 2011, pp. 76-77.

"Entrevista exclusiva a la destacada poeta chilena Damsi Figueroa: 'A los cinco años ya jugaba a hacer libros"'. Julio Fernando San Martín. Valija Cultural. 6 de marzo de 2013. Recuperado de: https://valijacultural.tumblr.com/ post/30568625636/entrevista-exclusiva-a-la-destacadapoeta-chilena

Gallardo, Andrés. "Visión del lenguaje en dos poetas jóvenes de Concepción". Estudios Filológicos, no. 40, 2005, pp. 96-106.

García, Mabel. "El proceso de retradicionalización cultural en la poesía mapuche actual: Üi de Adriana Paredes Pinda". Revista Chilena de Literatura, no. 81, 2012, pp. 51-68.

Huenún, Jaime Luis. Reducciones. Santiago: LOM, 2012.

Kvyeh, Rayen. "Todo termina, pero la tierra nunca termina, siempre se queda". Mapucheinfo, 1990. Recuperado de: http://www.mapuche.info/lumaco/rayen00.htm

Luna de cenizas. Gulumapu-Temuko, Ñuke Mapu, 1992.

PAZcificación del Wallmapu. El despojo en manos del Estado en el territorio mapuche. Temuko, Editorial independiente, 2017.

León, Pilar. "Ejecutivos de Celulosa Arauco serán formalizados por contaminación a río Cruces". DiarioUChile, 2019. Recuperado de: https://radio.uchile.cl/2019/01/13/ejecutivos-decelulosa-arauco-seran-formalizados-por-contaminacion-ario-cruces/

Mbembe, Achille. Necropolitica. Trad. Elisabeth Falomir Archambault. Santa Cruz de Tenerife, Melusina, 2011.

Mellor, Mary. Feminismo y ecología. Trad. Ana María Palos. México, D.F., Siglo XXI, 2000.

Mora, Ziley. Zungun. Diccionario mapuche. Palabras que brotan de la tierra. Santiago de Chile, Uqbar Editores, 2016.

Moraga, Fernanda. "La emergencia de un corpus poético de mujeres mapuche". Kümedungun/Kümewirin. Antología poética de 
mujeres mapuche (siglos XX-XXI). Ed. Maribel Mora Curriao y Fernanda Moraga. Santiago de Chile: LOM ediciones, 2010, pp. 221-245.

Munizaga, Mónica. Las voces del trance: estudio crítico de la obra poética de Adriana Paredes Pinda. Valdivia, Ser Indígena Ediciones, 2011.

Nahuelpan, Héctor. "Micropolíticas mapuche contra el despojo en el Chile neoliberal. La disputa por el lafkenmapu (territorio costero) en Mehuín". Izquierdas, no. 30, 2016, pp. 89-123.

Namuncura, Domingo. Ralco: ¿represa o pobreza? Santiago de Chile, LOM ediciones, 1999.

Pairicán, Fernando. Malon. La rebelión del movimiento mapuche 19902003. Santiago de Chile, Pehuén, 2016.

Paredes Pinda, Adriana. Üi. Santiago de Chile, LOM ediciones, 2005. "La pluma del picaflor del agua". Zomo Newen. Relatos de vida de mujeres mapuche en su lucha por los derechos indígenas. Coord. Elisa García Mingo. Santiago de Chile, LOM ediciones, 2017, pp. 161-204.

Prieto, Manuel. "La ecología (a)política del modelo de aguas chileno". Ecología política en Chile. Naturaleza, propiedad, conocimiento y poder. Eds. Beatriz Bustos, Manuel Prieto y Jonathan Barton. Santiago de Chile, Editorial Universitaria, 2015, pp. 143-164.

Puleo, Alicia H. Ecofeminismo. Para otro mundo posible. Madrid, Cátedra, 2011.

Reyes, Luis Alberto. El pensamiento indígena en América. Los antiguos andinos, mayas y nahuas. Buenos Aires, Biblos, 2009.

Sánchez Martínez, Juan Guillermo. "Los esbirros no han logrado / apagar la luz de la luna": Rayen Kvyeh". Maguaré, vol. 29, no. 1, 2015, pp. 21-53.

Shiva, Vandana. Biopiratería. El saqueo de la naturaleza y el conocimiento. Trad. Isabel Bermejo. Barcelona, Icaria, 2001. Las guerras del agua. Privatización, contaminación y lucro. Trad. Susana Guardado. México D.F., Buenos Aires, Siglo XXI, 2004.

Skewes, Juan Carlos y Marta Silva. "Elementos para una comprensión ecológico cultural de las narraciones míticas acerca de las 
aguas y los seres del agua en la cosmovisión mapuche huilliche". Sociedad y cultura: reflexiones transdisciplinarias. Comp. Claudia Rodríguez, Rodrigo Browne, Carlos del Valle y Sebastián Figueroa. Valdivia, Universidad de la Frontera, Universidad Austral de Chile, 2007, pp. 129-138

Skewes, Juan Carlos, Solari, María Eugenia, Guerra, Debbie y Daniela Jalabert. "Los paisajes del agua: naturaleza e identidad en la cuenca del río Valdivia". Chungará, no. 44, 2012, pp. 299-312.

Tapia González, Aimé. Mujeres indígenas en defensa de la tierra. Madrid, Cátedra, 2018. 